\title{
On Paths of Professional Skills Contests to Improve Integration of Education with Industries
}

\author{
Chunyan Liu \\ Hunan Mechanical and Electrical Polytechnic, Hunan 410151, China. \\ 458697871@qq.com
}

Keywords: Vocational skill contest, integration of vocational education with industries, paths.

\begin{abstract}
With the aim of contest boosting teaching and vocational education development, this essay made an analysis of the skillful talents need in equipment manufacturing in Hunan through investigation and research. Through the skill contests, we can improve the quality, broaden the way and enhance the promotional effects of students' employment. Furthermore, we can speed up the service for the regional economies, and push forward integration of vocational education with industries and the structural reform on supply side.
\end{abstract}

\section{Introduction}

As the designation and innovation of the significant system of the vocational education of China, the National Skills Contest of Vocational Colleges, from its very beginning, has enhanced the influence and attraction on vocational education and has played a positive role in boosting integration of vocational education with industries and the structural reform on supply side.

Based on items determined by the National Skills Contest of Vocational Colleges, with the purpose to show the specialized features of vocational colleges, combining the industrial structure characteristics, the annual Skills Contest of Vocational Colleges of Hunan Province worked out the Compiled System of Skills Contest of Vocational Colleges of Hunan, which help construct the persistent effective mechanism of the contest and make it normalized. The contents of the system includes the following: the working requirement of contest fields; preparation of contest fields and the concerning requirements; the procedures and requirements of contests; rules on score decision; results judgments; contest items management methods; draw of contestants; and the preliminary instructions.

As one of the contest fields of equipment manufacturing of vocational college group in Skills Contest of Vocational Colleges of Hunan, in line with the Compiled System of Skills Contest of Vocational Colleges of Hunan, Hunan Mechanical and Electrical Polytechnic found a work party. According to the requirements of professional skills and the characteristics of students' interests, it divided all contestants into different groups as following: the applied group of industrial robotic technique, the installing and debugging group of automatic production line. Based on contesting criteria of equipment manufacturing, combining evaluation on talents employment in equipment manufacturing, HMEP brought the skills, techniques and production procedures into its system of course teaching and talents cultivation to form new paths in integration of vocational education with industries and in talents cultivation of equipment manufacturing, which will complement and benefit mutually.

\section{Organization of the Text}

\subsection{An Analysis on Influence That Development of Equipment Manufacturing of Hunan Exerts} on Supply and Demand of Skillful Talents.

After the 19th Session of National Congress of the Communist Party of China, in the 3 major strategies of state, Hunan, located in transitional zone, greatly benefits from the proposal of B\&R. As practicing B\&R proposed by General Secretary Xi Jinxing when visiting Hunan, Hunan Province based itself on promoting development of regional economy, speeding up construction of its modern 
industrial system, using high and new technology to achieve strategic breakthrough on structural adjustment with the lead of advanced industries, carrying out the landmark projects which aims at constructing the modern bases with intelligent manufacturing demonstration of China. Hunan will give a high priority to intelligent manufacture to promote its equipment and strengthen its manufacturing industry, realizing a historical leap from "Made in Hunan "to "Intelligent Manufacture in Hunan". Industries 4.0, on the background of intelligent manufacturing, gave much attention to digital, green manufacturing and the application of new forms of energy and new materials, and focusing on the influence of the technological revolution on the transformation and upgrading of equipment industry. The changes of the future equipment industry of Hunan Province will take place as the following: production technology being advanced, manufacturing and service being integrated, industrial organization being clustered, products being more competitive over the world. At present, through a survey of the key manufacturing enterprises within Hunan, especially those within Changsha-Zhuzhou-Xiangtan city group, for the characteristics of the posts, the increase of demand for talents of high technology on research and development in advanced equipment manufacturing will soar up to $92 \%$, and for highly skilled talents of operation will go up to $56.2 \%$, while demand for interdisciplinary talents of advanced management with sensitivity to Internet and the international vision will fall to only $22.4 \%[1]$.

Equipment manufacturing is a significant means and the industrial carrier to make high technology transform into real productivity, which is characterized as high-technological, integrating and intelligent zed. Therefore, according to its developing directions, combining the two contest items our college will participate in, HMEP made an analysis on demand for the applied talents in equipment manufacturing enterprises in Changsha-Zhuzhou-Xiangtan city group through investigation and research.

The robots manufacturing or applied enterprises, such as Hunan Sanchuan Robot Corporation, GAC Fiat, GMMC, offer the space for home-made robots in industrial designation, software and hardware development, esp. the program system and reducing gear. They also have a good demand for talents in integrated application, conceptual designation, programmer and mechanical debugging, who are suit for the posts of the installation, debugging, operation and maintenance of the industrial robots. Talents with practical experience of production and management, and with spirits of innovation and service, who master the basic theory and operating skills of industrial robot technology and are able to independently install, program, debug, maintain, operate and manage the industrial robots, are badly in need. Talents are also required to adapt to posts of maintenance of industrial robotic system, the installation, debugging, and maintenance operation management of industrial robotic workstation. They should have a good command of basic knowledge of construction and motion principles of average industrial robots, as well as skills to install and debug, program and operate, maintain and repair the robots. They should also have good production abilities to meet the requirements for applied techniques of industrial robots. In addition, they should be cooperative, hardworking, diligent and professional.

Some automatic production line manufacturers and applied enterprises, such as Hunan Yingfeila Automation Technology Co., Ltd., Hunan blue sky Intelligent Equipment Technology Co., Ltd. , Hunan Tingyi Automation Co., Ltd. , Hunan Jiangmen electromechanical automation equipment Co., Ltd., Hunan Yankee Electric Power Technology Co., Ltd., Hunan Tong Yuan mechanical and Electrical Technology Co., Ltd., Hunan Jialing Intelligent Equipment Co., Ltd., Hunan Wen Chao automation equipment Technology Co., Ltd., Hunan Lens Technologies Inc., employ automatic production line to maintain products' features of prospect and stability in designation and productive techniques[2]. They all need talents for installation, debugging, operation, maintenance, repair and testing. And demand for talents, esp. technical supervisors, maintenance engineers, technical engineers, system integration engineers, drafting engineers, mechanical and electrical engineers, construction managers, electrical engineers in fields as application technology development, technology import and technical transformation of automatic production equipment, has far outstripped the supply. The talents are required to have a good command of basic knowledge and operational skills of Mechatronics, and be able to deal with the tasks of manufacturing, installation, 
debugging, maintenance, operation and technological management of automatic controlling system and production equipment. The talents should also have good practical experience and innovative abilities to adapt to posts of electrical and electronic skills, computer control, material transfer skills, sensors examination skills, programmable controller, the basic theory and application of frequency conversion, skills to manage, maintain and assemble automatic production lines, and PLC assembling.

\subsection{The Paths of Integration of Vocational Education with Industries Boosted by Contest Items of Equipment Manufacturing in Skills Contests.}

All talents gather to discuss over produce wisely, and all teachers gather to improve vocational education. Based on the items of equipment manufacturing contest, HMEP, considering the equipment manufacturing enterprises' demand for talents, tried to show its professional core abilities and cover the specialized knowledge and skills to improve employment quality.

Taking the group of applied industrial robotic skills as an example, this contest item uses the industrial robotic workstation system as the contest platform, with 3 contestants coordinating together to finish the tasks as following: to install the robot of the workstation system and the mechanic and electrical system of its peripheral equipment; to calibrate the industrial robots; to debug communication settings, operating and visual system programming; to program robots off-line; and to debug AGV robots and robots palletizer. In addition, through the development of man-machine interface system, they have to the comprehensive tasks of completing the online operation of intelligent industrial robotic workstation system and specific manufacturing procedures. Base on the procedures of installation, programming, debugging, maintenance and operational management, as well involving the contents as application development, pre-sales, sales and production management, maintenance of programmable control system, which include some core professional knowledge of 6 axis joint type industrial robots, AGV mobile robots, intelligent visual robots, robots palletizer, intelligent manufacturing, electronics, mechanism, air operation, sensors, programmable control system, industrial networks, it can show the students' techniques in industrial robotic programming, interface, visual identification, intelligent examination, PLC control, servo control, electrical and mechanical system installation and debugging, maintenance and fault detection, and it can also improve the contestants' professionalism in management, teamwork, efficiency, safety, quality and cost control. All the technical specifications should accord with National Occupational Standard for maintenance of electricians (career coding 6-07-06-05), National professional standards for tool fitter (career coding 6-05-02-02), National standard for assembly of fitter (career coding 6-05-02-01), National professional standards for mechanical equipment installation workers (career coding 6-23-10-01), National professional standards for programmable control system designers (career coding X2-02-13-10), General technical conditions standard for assembly robot (career coding GBT 26154-2010), Safety Specification for industrial robots (GB 11291-1997).

The contest items will contribute to cultivation of talents of industrial robots operation, programming, workstation installation and debugging, system integration and scenic maintenance in industrial robots manufacturing and system integration and application, which the enterprises need mostly. These talents will be engaged in industries as automobile, machining, food, electronics, taking jobs in need of applied skills as scenic programming of operational units, debugging and maintenance, fault diagnosis, man-machine interface, touch screen programming in automatic complete set equipment, as well as jobs as sales and after-sale service of industrial robotic technology.

Guided and supported by Department of Human Resources and Security of Hunan Province, Municipal Commission of Economy and Information Technology of Hunan Province and Department of Education of Hunan Province, HMEP undertook two provincial contesting items of equipment manufacturing, the applied industrial robotic techniques and the installing and debugging of automatic production line, which provided security for HMEP. Since 2012, in contest of the installing and debugging of automatic production line, the number of attending team and contestants have considerably increased, from 12 teams and 24 contestants in 2012 to 21 teams and 42 contestants in 2018 with qualified competition. Another contest of applied industrial robotic 
techniques, conducting since 2016, with efforts of industrial association and organization as Hunan Institute of Machine Tools and Molds, Robot and Intelligent Equipment Division and Institute of Automation, was successively held by Jiangsu Huambo Robot Co., Ltd., Tianjin Boron Robot Co., Ltd., Hunan Albert Robot Co., Ltd., Hunan Yuan Intelligent Equipment Co., Ltd., and Hunan Shantou Intelligent Equipment Co., Ltd., made the contest proposition reflecting the skill's latest task requirement and operational standards of techniques. Through the contest platform, the students exhibiting excellent skills in contests will be employed by the enterprises cooperating with colleges, which can integrate the demand and supply of the talents.

The success of the contest boosts the positive interaction between college and enterprises. By the end of 2017, there were 20 enterprises established deep cooperation with HMEP. One of the contestant, who won second-class award in provincial contest of the installing and debugging of automatic production line in 2012, was recruited directly as group leader by GAC Fiat. Another contestant, won second-class award in provincial contest in 2013, was employed directly as production technology administrator in Hunan Shantou Intelligent Equipment Co., Ltd. Contestants who won first-class award in provincial contests in 2015 and 2017, were hired as technical research and development backbones in Hunan Yuan Intelligent Equipment Co., Ltd. and GMMC. Contestants, who respectively won first-class award in provincial contest of the applied industrial robotic techniques in 2016 and 2017, were all selected by Lens Intelligent Robots Co., Ltd. and Hunan Yamuna Intelligent Equipment Co., Ltd. Therefore, through contest platform, colleges can attract more good enterprises to carry out deeper integration of vocational education with industries, which not only can integrate the development in science and technology, and human resources, but most importantly can offer students opportunities to display their own abilities to boost employment.

\subsection{Enhance the Public Effects on Employment through the Contest Platform.}

Serving as a propaganda window for promoting products of enterprises and propagating the latest science and technology of the industry, with the state-owned, private and foreign enterprises and joint ventures, skill contests can cooperate with them to achieve mutual benefit through characteristic education to cultivate talents.

The provincial contests are sponsored by Hunan Create robot Co., Ltd., with techniques and equipment provided by Jiangsu Hue Bo Robot Technology Co., Ltd. and Tianjin Bono robot Co., Ltd. During the event, Hunan About robot Co., Ltd. and Hunan Yamuna Intelligent Equipment Co., Ltd. were invited for cooperation. They could display their own products, propagating their own characteristics to establish a more favorable impression. Meanwhile, HMEP launched a technical festival centered on contests of designation of electronic products, mechanic and technological innovation to display its concepts of talents cultivation to cooperating enterprises and other colleges. And it also started a creation festival with main theme of create dream in HMEP and create to win the future, which could help to improve its faculty and students' innovation abilities and create atmosphere for creation.

The contests and creation festivals were valued by superior units as Hunan provincial science and Technology Department, The Education Department of Hunan Province, Changsha Municipal Science and Technology Bureau, Changsha County Science and Technology Bureau. Some relevant directors visited on the spot and offered valuable advice. The industry associations, such as Branch of Hunan robot and artificial intelligence, Robot and intelligent equipment division and Changsha robot industrial innovation strategic alliance, came to HMEP to help develop the integration and cooperation of education with industries. The college constructed discipline groups as intelligent control technology, intelligent manufacturing technology, smart cars and intelligent service to integrate with local strategic new industries, which will form the characteristic integration of education with industry to serve the local economy.

\section{Acknowledgments}

This work was financially supported by a planned science and research project of the Fourth Session of China Institute of Vocational and Technical Education (2014-2015): A Study on 
Implementation Mechanism of Win-win Cooperation between Colleges and Enterprises in Integration of Vocational Education with Industries (201418Y08).

\section{References}

[1]. Beijing Net Employment Consulting Co., Ltd. Changsha branch an analysis report on supply and demand of high-end talents in strategic emerging industries in Hunan (2017-2018) http://www.docin.com/p-1862480709.html.

[2]. Zhang son Gwen, installation and debugging of automatic production lines, Electronic Technology \& Software Engineering, Vol.08 (2014) No.4, p. 261. 